\title{
GUIDELINES
}

\section{European S3-Guidelines on the systemic treatment of psoriasis vulgaris - Update 2015 - Short version - EDF in cooperation with EADV and IPC}

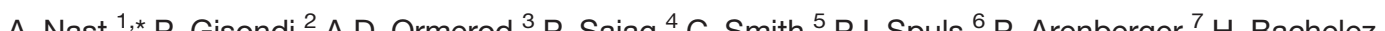
J. Barker, ${ }^{9}$ E. Dauden, ${ }^{10}$ E.M. de Jong, ${ }^{11}$ E. Feist, ${ }^{12}$ A. Jacobs, ${ }^{1}$ R. Jobling, ${ }^{13}$ L. Kemény, ${ }^{14}$ M. Maccarone, ${ }^{15}$ U. Mrowietz, ${ }^{16}$ K.A. Papp,${ }^{17}$ C. Paul, ${ }^{18}$ K. Reich, ${ }^{19}$ S. Rosumeck, ${ }^{1}$ T. Talme,${ }^{20}$ H.B. Thio, ${ }^{21}$ P. van de Kerkhof, ${ }^{22}$ R.N. Werner, ${ }^{1}$ N. Yawalkar ${ }^{23}$

${ }^{1}$ Division of Evidence Based Medicine, Department of Dermatology, Charité - Universitätsmedizin Berlin, Berlin, Germany

${ }^{2}$ Section of Dermatology and Venereology, Department of Medicine, University of Verona, Verona, Italy

${ }^{3}$ Department of Dermatology, Aberdeen Royal Infirmary, Aberdeen, UK

${ }^{4}$ Service de Dermatologie, Hôpital Ambroise Paré Université Paris V, Boulogne, France

${ }^{5}$ Clinical Lead for Dermatology, St Johns Institute of Dermatology, St Thomas' Hospital, London, UK

${ }^{6}$ Department of Dermatology, Academic Medical Center, Amsterdam, The Netherlands

${ }^{7}$ Third Faculty of Medicine, Department of Dermatology, Charles University, Prague, Czech Republic

${ }^{8}$ Department of Dermatology, Hôpital Saint-Louis, Paris, France

${ }^{9}$ St. Johns Institute of Dermatology, St. Thomas' Hospital, London, UK

${ }^{10}$ Hospital Universitario de la Princesa, Madrid, Spain

${ }^{11}$ University Medical Center Nijmegen St Radboud, Nijmegen, The Netherlands

${ }^{12}$ Medizinische Klinik mit Schwerpunkt Rheumatologie u. Klinische Immonologie, Charité - Universitätsmedizin Berlin, Berlin, Germany

${ }^{13}$ Cambridge, UK

${ }^{14}$ SZTE Borgyogyaszati Klinika, Szeged, Hungary

${ }^{15}$ Roma, Italy

${ }^{16}$ Department of Dermatology, Psoriasis-Center University Medical Center Schleswig Holstein, Kiel, Germany

${ }^{17}$ Waterloo, Canada

${ }^{18}$ Department of Dermatology, Paul Sabatier University, Toulouse, France

${ }^{19}$ Dermatologikum Hamburg, Hamburg, Germany

${ }^{20}$ Section of Dermatology and Venereology, Department of Medicine, Karolinska Institutet, Karolinska University Hospital, Huddinge,

Stockholm, Sweden

${ }^{21}$ Department of Dermatology, Erasmus University, Rotterdam, The Netherlands

${ }^{22}$ Department of Dermatology, University Hospital Nijmegen, Nijmegen, The Netherlands

${ }^{23}$ Department of Dermatology, Inselspital, Universitätsklinik für Dermatologie, Bern, Switzerland

*Correspondence: A. Nast. E-mail: alexander.nast@charite.de

Received: 22 June 2015; Accepted: 7 July 2015

\section{Conflicts of interest}

All authors declared their potential conflicts of interest. A detailed list is available in the methods report

(DOI: 10.1111/jdv.13353).

\section{Funding sources}

The guidelines project has kindly been supported by the EDF. The financial support did not influence the guidelines development and context.

\section{Introduction}

This is an executive summary of all consented recommendations of the European Psoriasis Guidelines - Update 2015. The long version of this guideline is available online as supplementary file. A detailed description of the used methodology can be found in the methods report (DOI: 10.1111/jdv.13353).

In brief, available evidence of the efficacy and safety of the systemic treatments for psoriasis including an assessment of the quality of evidence was summarized using GRADE (Grading of Recommen- dations Assessment, Development and Evaluation). ${ }^{1}$ The end of the literature search was October 12th, 2014. Some parts of the guidelines are based on a complete literature review (marked as evidence based), other parts are based on expert consensus only (marked as expert opinion). All recommendations (highlighted in grey) were formulated and consented by an expert panel, officially nominated by the European Dermatology Forum (EDF), the European Association for Dermatology and Venereology (EADV) or the International Psoriasis Council (IPC). 
Table 1 Strength of recommendations: wording, symbols and implications $s^{4,5}$

\begin{tabular}{ll}
\hline Strength & Wording \\
\hline Strong recommendation for the use of an intervention & 'We recommend ...' 'We suggest ...' \\
\hline Weak recommendation for the use of an intervention & 'We cannot make a recommendation with respect to ...' \\
\hline No recommendation with respect to an intervention & 'We suggest not ...' \\
\hline Weak recommendation against the use of an intervention & 'We recommend not ...' \\
\hline Strong recommendation against the use of an intervention & $\downarrow$ \\
\hline
\end{tabular}

For the chapters of 'Special considerations and special patient populations', the literature was not systematically assessed and the recommendations are based on expert opinion only.

All recommendations were consented using formal consensus methodology (Delphi process or consensus conference with nominal group technique). ${ }^{2,3}$ Based on the GRADE approach, the strength of recommendation is expressed by the wording and symbols shown in Table 1.
For each recommendation, the strength of consensus in terms of percentage of agreement was measured and documented. Three levels of consensus were defined and distinguished: 'strong consensus' (agreement of $>90 \%$ of the members of the expert group), 'consensus' (75-89\% agreement) and 'weak consensus' (50-74\% agreement).

The guidelines have a validity until 31.12.2019.

\section{Conventional systemic therapy}

\section{Acitretin}

Instructions for use

Pre-treatment

- Objective assessment of the disease (such as PASI/BSA/PGA; arthritis)

- HRQoL (such as DLQI/Skindex-29 or -17)

- History and clinical examination should focus on musculoskeletal problems. If patient reports complaints, further imaging investigation may be performed

- Exclude pregnancy/breastfeeding: patient must be informed explicitly and extensively about the teratogenic risk of the medication, the necessity of effective long-term contraception (at least two years after cessation of treatment) and the possible consequences of a pregnancy while taking retinoids; written documentation of this informational interview

- Note that during and up to one year after treatment, blood donation is not permitted

- Laboratory controls (see Table 2)

\section{During treatment}

- Objective assessment of the disease (such as PASI/BSA/PGA; arthritis)

- HRQoL (such as DLQI/Skindex-29 or -17)

- Take capsules with a fatty meal or with whole milk

- Avoidance of pregnancy is mandatory. Start treatment on second or third day of the menstrual cycle, after satisfactory contraception for at least one month prior to treatment. Double contraception is recommended (e.g. condom + pill; IUD/ Nuva Ring + pill; cave: no low-dosed progesterone preparations/mini-pills) during and up to two years after the end of therapy; effectiveness of oral contraceptives is reduced by acitretin

- Avoidance of alcohol

- Ask patient about spine and joint complaints at follow-up visits. If patient reports complaints, further imaging investigation may be performed

- Laboratory controls (see Table 2)

Post-treatment

- Reliable contraception in women of child-bearing age for up to two years after therapy, double contraception, as described above, is recommended

- Patients may not donate blood for up to one year after the discontinuation of therapy 
Table 2 Recommended lab controls - acitretin

\begin{tabular}{|c|c|c|c|c|c|c|c|}
\hline \multirow[t]{2}{*}{ Parameter } & \multicolumn{7}{|c|}{ Period in weeks } \\
\hline & Pre-treatment & 1 & 2 & 4 & 8 & 12 & 16 \\
\hline Blood count ${ }^{\star}$ & $x$ & & & & $x$ & & $x$ \\
\hline Liver enzymes** & $\mathrm{x}$ & & & $\mathrm{x}$ & $\mathrm{x}$ & & \\
\hline Serum creatinine & $x$ & & & & & & \\
\hline Pregnancy test (urine) & $x$ & \multicolumn{6}{|c|}{ Monthly up to 2 years after therapy (see national regulations) } \\
\hline Fasting blood glucose & $\mathrm{x}$ & & & & & & \\
\hline Triglycerides, cholesterol, HDL & $\mathrm{x}$ & & & $x$ & & & $\mathrm{x}$ \\
\hline
\end{tabular}

${ }^{*} \mathrm{Hb}, \mathrm{Hct}$, leucocytes, platelets.

${ }^{\star \star} \mathrm{AST}, \mathrm{ALT}, \mathrm{AP}, \gamma \mathrm{GT}$.

Therapeutic recommendations

\begin{tabular}{l|l}
\hline Recommendation & Strength of consensus \\
\hline $\begin{array}{l}\text { Based on the available evidence we cannot make a recommendation for } \\
\text { or against the use of acitretin as a monotherapy. }\end{array}$ & Consensus \\
\hline $\begin{array}{l}\text { Based on clinical experience and depending on the most important } \\
\text { outcome for the individual patient, we suggest a low dose (20-30 mg } \\
\text { daily) with respect to tolerability and a high dose (>30 mg daily) with } \\
\text { respect to efficacy. }\end{array}$ & \begin{tabular}{l} 
Consensus \\
\hline
\end{tabular} \\
\hline
\end{tabular}

\section{Therapeutic combinations}

\begin{tabular}{llll}
\hline Recommendation & Strength of consensus & Comments \\
\hline Adalimumab & 0 & Consensus & No evidence available \\
\hline Ciclosporin & $\downarrow$ & Strong consensus & Expert opinion: competition cytochrome P450 inactivation \\
\hline Etanercept & $\uparrow$ & Consensus & Expert opinion: good safety profile assumed, possibly increased efficacy \\
\hline Fumaric acid esters & 0 & Consensus & No evidence available \\
\hline Infliximab & 0 & Consensus & No evidence available \\
\hline Methotrexate & $\downarrow$ & Strong consensus & Expert opinion: increased risk of hepatotoxicity possible \\
\hline Ustekinumab & 0 & Consensus & No evidence available \\
\hline
\end{tabular}




\section{Ciclosporin}

Instructions for use

\section{Pre-treatment}

- Objective assessment of the disease (such as PASI/BSA/PGA; arthritis)

- HRQoL (such as DLQI/ Skindex-29 or -17)

- History and clinical examination should focus on previous and concomitant diseases (e.g. arterial hypertension; severe infections; malignancies, including cutaneous malignancies; renal and liver diseases) and concomitant medication (see Drug interactions, long version)

- Measurement of blood pressure on two separate occasions

- Laboratory controls (see Table 3)

- Reliable contraception (cave: reduced efficacy of progesterone-containing contraceptives)

- Regular gynaecologic screening according to national guidelines

- Consultation on vaccination; susceptibility to infections (take infections seriously, seek medical attention promptly); drug interactions (inform other treating physicians about therapy); avoidance of excessive sun exposure; use of sunscreens

\section{During treatment}

In uncomplicated long-term therapy with low-dose ciclosporin (CSA; 2.5-3 $\mathrm{mg} / \mathrm{kg}$ daily), follow-up intervals may be extended to two months or more. Shorter intervals may be needed in patients with risk factors, dose increases, or those who must take concomitant medications that are likely to contribute to ADR. In selected patients with intermittent and short-term treatment, less strict monitoring (regular checking of blood pressure and creatinine level) may be sufficient.

- Objective assessment of the disease (such as PASI/BSA/PGA; arthritis)

- HRQoL (such as DLQI/Skindex-29 or -17)

- Clinical examination should focus on the status of skin and mucous membranes (hypertrichosis, gingival changes), signs of infections, gastrointestinal or neurological symptoms (tremor, dysaesthesia) and musculoskeletal/joint pain

- Repeat recommendation for sun avoidance and sun protection

- Check of concomitant medication

- Measurement of blood pressure

- Laboratory controls (see Table 3)

- Reliable contraception

- Regular gynaecologic screening according to national guidelines

- If creatinine is significantly elevated and/or patient on therapy for $>1$ year, perform creatinine clearance (or creatinineEDTA clearance where available).

- Determination of the CSA level is recommended in individual cases.

\section{Post-treatment}

- After discontinuation of CSA, patients should be followed up for skin cancer, especially in case of extensive prior therapeutic or natural UV exposure. 
Table 3 Recommended lab controls - ciclosporin

\begin{tabular}{|c|c|c|c|c|c|c|}
\hline \multirow[t]{2}{*}{ Diagnostics } & \multicolumn{6}{|l|}{ Period in weeks } \\
\hline & Pre-treatment & 2 & 4 & 8 & 12 & 16 \\
\hline Full blood count* & $x$ & $x$ & $x$ & $x$ & $x$ & $x$ \\
\hline Liver values ${ }^{\star \star}$ & $x$ & $x$ & $x$ & $\mathrm{x}$ & $x$ & $x$ \\
\hline Electrolytes $^{\star * *}$ & $x$ & $x$ & $x$ & $x$ & $x$ & $x$ \\
\hline Serum creatinine & $x$ & $x$ & $x$ & $x$ & $x$ & $x$ \\
\hline Urine status & $x$ & & $x$ & & & $x$ \\
\hline Uric acid & $x$ & & $x$ & $x$ & $x$ & $x$ \\
\hline Pregnancy test (urine) & $x$ & & & & & \\
\hline Cholesterol, triglycerides & $\mathrm{X}^{\star \star \star \star}$ & & & $x$ & & $x$ \\
\hline Magnesium ${ }^{\star \star \star \star \star}$ & $x$ & & & $x$ & & $x$ \\
\hline $\mathrm{HBV} / \mathrm{HCV}$ & $\mathrm{x}$ & & & & & \\
\hline HIV & $x$ & & & & & \\
\hline \multicolumn{7}{|c|}{$\begin{array}{l}\text { Not all tests may be necessary for all patients. Patient history, risk exposure and patient } \\
\text { characteristics have to be taken into account. Further specific testing may be required according to } \\
\text { clinical signs, risk and exposure. }\end{array}$} \\
\hline
\end{tabular}

*Erythrocytes, leucocytes, platelets.

**Transaminases, AP, $\gamma \mathrm{GT}$, bilirubin.

${ }^{* * \star}$ Sodium, potassium.

${ }^{* * * *}$ Recommended two weeks before and on the day of treatment initiation (fasting).

$\star \star \star \star \star$ Only with indication (muscle cramps).

\section{Therapeutic recommendations}

\begin{tabular}{lll}
\hline Recommendation & \multicolumn{1}{c}{ Strength of consensus } \\
\hline $\begin{array}{l}\text { If a short course for induction treatment is intended we recommend } \\
\text { CSA. }\end{array}$ & $\uparrow \uparrow$ & Strong consensus \\
\hline $\begin{array}{l}\text { For long-term treatment we suggest CSA only in selected patients. } \\
\text { In case of continuous long-term treatment, we suggest CSA for a } \\
\text { maximum of up to two years. }\end{array}$ & $\uparrow$ & Strong consensus \\
\hline $\begin{array}{l}\text { In case a longer treatment is needed, we suggest the consultation } \\
\text { with a nephrologist. }\end{array}$ & $\uparrow$ & Consensus \\
\hline $\begin{array}{l}\text { Based on weighting of risk and benefit we suggest using CSA with a } \\
\text { starting dose of } 2.5 \mathrm{mg} / \mathrm{kg} \text { bodyweight QD for up to four weeks, with } \\
\text { a dosage increase up to } 5 \mathrm{mg} / \mathrm{kg} \text { bodyweight once daily thereafter. }\end{array}$ & $\uparrow$ & Weak consensus \\
\hline
\end{tabular}

\section{Therapeutic combinations}

\begin{tabular}{llll}
\hline Recommendation & & Strength of consensus & Comments \\
\hline Acitretin & $\downarrow$ & Strong consensus & Expert opinion: competition cytochrome P450 inactivation \\
\hline Adalimumab & $\downarrow$ & Consensus & Expert opinion: increased risk of immunosuppression \\
\hline Etanercept & $\downarrow$ & Consensus & Expert opinion: increased risk of immunosuppression \\
\hline Fumaric acid esters & $\circ$ & Consensus & No evidence available \\
\hline Infliximab & $\downarrow$ & Consensus & Expert opinion: increased risk of immunosuppression \\
\hline Methotrexate & $\downarrow$ & Weak consensus & Expert opinion: increased risk of immunosuppression \\
\hline Ustekinumab & $\downarrow$ & Consensus & Expert opinion: increased immunosuppression, anecdotal evidence of increased toxicity \\
\hline
\end{tabular}




\section{Fumaric acid esters}

Instructions for use

Pre-treatment

- Objective assessment of the disease (such as PASI/BSA/PGA; arthritis)

- HRQoL (such as DLQI/Skindex-29 or -17)

- History and clinical examination

- Laboratory controls (see Table 4)

During treatment

- Objective assessment of the disease (such as PASI/BSA/PGA; arthritis)

- HRQoL (such as DLQI/Skindex-29 or -17)

- Clinical examination

- Laboratory controls (see Table 4)

Post-treatment

- None.

Table 4 Recommended lab controls - fumaric acid esters

\begin{tabular}{|c|c|c|c|c|}
\hline \multirow[t]{2}{*}{ Parameter } & \multicolumn{4}{|c|}{ Period in weeks } \\
\hline & Pre-treatment & Month 1 & $\begin{array}{l}\text { Every } 4 \text { weeks until } \\
\text { month } 4\end{array}$ & Thereafter \\
\hline Liver enzymes & $x$ & $x$ & $x$ & every 8 weeks \\
\hline Serum creatinine & $x$ & $x$ & $x$ & every 8 weeks \\
\hline Urine status & $x$ & $x$ & $x$ & every 8 weeks \\
\hline Pregnancy test & $x$ & & & \\
\hline Blood count* & $x$ & $x$ & $x$ & every 4 weeks ${ }^{\star *}$ \\
\hline \multicolumn{5}{|c|}{$\begin{array}{l}\text { Not all tests may be necessary for all patients. Patient history, risk exposure and patient characteristics have } \\
\text { to be taken into account. Further specific testing may be required according to clinical signs, risk and } \\
\text { exposure. }\end{array}$} \\
\hline
\end{tabular}

*If leukocytes are $<3000 / \mu l$, fumarate therapy needs to be stopped. If lymphocytes are $<700 / \mu l$, patients should be kept on half of the last dose for $2-4$ weeks and stopped if lymphocytes remain below 700/ $\mu$; if lymphocytes are $<500 / \mu l$, treatment must be terminated.

${ }^{\star *}$ Frequency of lab control of blood count was a matter of debate, including repeated Delphi voting. No strong consensus was achieved, the recommendation passed with 'weak consensus' (63\%).

\section{Therapeutic recommendations}

\begin{tabular}{|c|c|c|c|}
\hline Recommendation & & Strength of consensus & Comment \\
\hline We recommend fumaric acid esters for the induction treatment. & $\uparrow \uparrow$ & Consensus & Evidence and consensus based \\
\hline We recommend fumaric acid esters for the long-term treatment. & $\uparrow \uparrow$ & Consensus & Expert opinion \\
\hline $\begin{array}{l}\text { We recommend fumaric acid esters with a slow increase dosing } \\
\text { regimen. }\end{array}$ & $\uparrow \uparrow$ & Consensus & Expert opinion \\
\hline
\end{tabular}


Therapeutic combinations

\begin{tabular}{llll}
\hline Recommendation & & Strength of consensus & Comments \\
\hline Acitretin & $\circ$ & Consensus & No evidence available \\
\hline Adalimumab & $\circ$ & Strong consensus & No evidence available \\
\hline Ciclosporin & 0 & Consensus & No evidence available \\
\hline Etanercept & 0 & Strong consensus & No evidence available \\
\hline Infliximab & $\downarrow$ & Consensus & Expert opinion: increased risk of immunosuppression, \\
& & & lymphocytopenia \\
\hline Methotrexate & $\downarrow$ & Consensus & Expert opinion: increased risk of immunosuppression \\
\hline Ustekinumab & 0 & Consensus & No evidence available \\
\hline
\end{tabular}

\section{Methotrexate}

Instructions for use

Pre-treatment

- History and clinical examination

- Objective assessment of the disease (such as PASI/BSA/PGA; arthritis)

- HRQoL (such as DLQI/Skindex-29 or -17)

- Laboratory parameters (see Table 5)

- Chest X-ray

- Contraception in women of child-bearing age (starting after menstruation), and also in men

- If abnormalities in liver screening are found, refer patient to specialist for further evaluation

During treatment

- Objective assessment of the disease (such as PASI/BSA/PGA; arthritis)

- HRQoL (such as DLQI/Skindex-29 or -17)

- Check concomitant medication

- Clinical examination

- Laboratory controls (see Table 5)

- Contraception in women of child-bearing age, and also in men

- $5 \mathrm{mg}$ folic acid once weekly, $24 \mathrm{~h}$ after MTX

Post-treatment

- Women must not become pregnant and men must not father a child for at least three months thereafter 
Table 5 Recommended lab controls - methotrexate

\begin{tabular}{|c|c|c|c|c|}
\hline \multirow[t]{2}{*}{ Parameter } & \multicolumn{4}{|c|}{ Period in weeks/months } \\
\hline & Pre-treatment & $\begin{array}{l}\text { After first } \\
\text { week }\end{array}$ & $\begin{array}{l}\text { During first two months, } \\
1 \times \text { every } 2 \text { weeks }\end{array}$ & $\begin{array}{l}\text { Thereafter, } \\
\text { every } 2-3 \text { months }\end{array}$ \\
\hline Blood count* & $x$ & $x$ & $x$ & $x$ \\
\hline Liver enzymes & $x$ & & $x$ & $x$ \\
\hline Serum creatinine & $x$ & & $x$ & $x$ \\
\hline Urine status & $x$ & & $x$ & $x$ \\
\hline Pregnancy test (urine) & $x$ & & & \\
\hline $\mathrm{HBV} / \mathrm{HCV}$ & $x$ & & & \\
\hline HIV & $x$ & & & \\
\hline Serum albumin ${ }^{\star *}$ & $x$ & & $x$ & $x$ \\
\hline PIIINP where available & $\mathrm{x}$ & & Every 3 months ${ }^{\star \star *}$ & \\
\hline \multicolumn{5}{|c|}{$\begin{array}{l}\text { Not all tests may be necessary for all patients. Patient history, risk exposure and patient characteristics have } \\
\text { to be taken into account. Further specific testing may be required according to clinical signs, risk and } \\
\text { exposure. }\end{array}$} \\
\hline
\end{tabular}

*If blood leucocytes $<3.0$, neutrophils $<1.0$, thrombocytes $<100$, or liver enzymes $>2 \times$ baseline values, decrease the dose or discontinue the medication.

**In selected cases (e.g. in cases with suspected hypoalbuminaemia or in patients using other drugs with high binding affinity for serum albumin).

*** Liver biopsy when necessary in selected cases; should be considered, for example, in patients with persistently abnormal PIIINP (>4.2 mcg/l in at least three samples over a 12-month period).

\section{Therapeutic recommendations}

\begin{tabular}{lll}
\hline Recommendation & & Strength of consensus \\
\hline We recommend MTX for the induction and long-term treatment. & $\uparrow \uparrow$ & Strong consensus \\
\hline $\begin{array}{l}\text { Methotrexate can be given by oral or subcutaneous delivery. In general, a } \\
\text { starting dose of } 15 \mathrm{mg} / \text { week is used but individual dosages can range from } \\
5 \text { to } 25 \mathrm{mg} / \text { week depending on individual factors. }\end{array}$ & Statement & Strong consensus \\
\hline
\end{tabular}

\section{Therapeutic combinations}

\begin{tabular}{|c|c|c|c|}
\hline Recommendation & & Strength of consensus & Comments \\
\hline Acitretin & $\downarrow$ & Strong consensus & Expert opinion: increased risk of hepatotoxicity possible \\
\hline Adalimumab & $\uparrow$ & Consensus & $\begin{array}{l}\text { Expert opinion: combination widely used in rheumatology; combination with low-dose MTX (e.g. } \\
7.5-10 \mathrm{mg} / \text { week is likely sufficient to reduce formation of anti-drug antibodies (ADA) and } \\
\text { increase trough levels of adalimumab) }\end{array}$ \\
\hline Ciclosporin & $\downarrow$ & Weak consensus & Expert opinion: increased risk of immunosuppression \\
\hline Etanercept & $\uparrow$ & Consensus & $\begin{array}{l}\text { Evidence (additional benefit of adding MTX to etanercept compared to etanercept monotherapy) } \\
\text { and consensus based }\end{array}$ \\
\hline Fumaric acid esters & $\downarrow$ & Consensus & Expert opinion: increased risk of immunosuppression \\
\hline Infliximab & $\uparrow$ & Consensus & $\begin{array}{l}\text { Expert opinion: combination widely used in rheumatology; combination with low-dose MTX (e.g. } \\
7.5-10 \mathrm{mg} / \text { week is likely sufficient to reduce formation of ADA and increase trough levels of } \\
\text { infliximab) }\end{array}$ \\
\hline Ustekinumab & 0 & Consensus & No evidence available \\
\hline
\end{tabular}




\section{Biological therapy}

\section{Adalimumab}

Instructions for use

Pre-treatment

- Physicians are encouraged to enrol their patients in a registry (if available)

- Objective assessment of the disease (such as PASI/BSA/PGA; arthritis)

- HRQoL (such as DLQI/Skindex-29 or -17)

- History and clinical examination should focus on prior exposure to treatments, malignancies, infections, congestive heart failure (CHF) and neurological disease or symptoms

- Recommended measures include:

- Check for skin cancer

- Check for lymphadenopathy

- Laboratory parameters (see Table 6)

- Exclusion of tuberculosis (see chapter 5.1 in long version)

- Check for evidence of active infection

- Contraception

During treatment

- Objective assessment of the disease (such as PASI/BSA/PGA; arthritis)

- HRQoL (such as DLQI/Skindex-29 or -17)

- Clinical examination should focus on malignancies, risk factors for serious infections, congestive heart failure and neurological symptoms

- Recommended measures include:

- Check for skin cancer

- Check for lymphadenopathy

- Laboratory parameters (see Table 6)

- Contraception

\section{Post-treatment}

- After discontinuation of adalimumab, patients should be followed up with medical history and physical examination

- Reliable contraception until five months after treatment, if applicable (according to the label) 
Table 6 Recommended lab controls - adalimumab

\begin{tabular}{|c|c|c|c|c|}
\hline \multirow[t]{2}{*}{ Parameter } & \multicolumn{4}{|l|}{ Period in weeks } \\
\hline & Pre-treatment & 4 & 12 & $\begin{array}{l}\text { Thereafter, } \\
\text { every } 3-6 \text { months }\end{array}$ \\
\hline Full blood count & $x$ & $x$ & $x$ & $x$ \\
\hline Liver enzymes & $\mathrm{x}$ & $x$ & $x$ & $x$ \\
\hline Serum creatinine & $x$ & $x$ & $x$ & $x$ \\
\hline Urine status & $x$ & $x$ & $x$ & $x$ \\
\hline $\begin{array}{l}\text { Pregnancy test } \\
\text { (urine) }\end{array}$ & $x$ & & & \\
\hline CRP & $x$ & & & \\
\hline $\mathrm{HBV} / \mathrm{HCV}$ & $x$ & & & \\
\hline HIV & $x$ & & & \\
\hline \multicolumn{5}{|c|}{$\begin{array}{l}\text { Not all tests may be necessary for all patients. Patient history, risk exposure and patient } \\
\text { characteristics have to be taken into account. Further specific testing may be required } \\
\text { according to clinical signs, risk and exposure. }\end{array}$} \\
\hline
\end{tabular}

\section{Therapeutic recommendations}

\begin{tabular}{lll}
\hline Recommendation & Strength of consensus & Comment \\
\hline $\begin{array}{l}\text { We recommend adalimumab as second-line medication* for the induction and } \\
\text { long-term treatment. }\end{array}$ & Strong consensus \\
\hline $\begin{array}{l}\text { We recommend using adalimumab with an initial loading dose of } 80 \mathrm{mg} \text { for week } 1, \\
\text { followed by } 40 \text { mg every other week. }\end{array}$ & Strong consensus \\
\hline
\end{tabular}

*If phototherapy and conventional systemic agents were inadequate in response or if they are contraindicated or not tolerated.

\section{Therapeutic combinations}

\begin{tabular}{llll}
\hline Recommendation & Strength of consensus & Comments \\
\hline Acitretin & 0 & Consensus & No evidence available \\
\hline Ciclosporin & $\downarrow$ & Consensus & Expert opinion: increased risk of immunosuppression \\
\hline Fumaric acid esters & 0 & Strong consensus & No evidence available \\
\hline Methotrexate & $\uparrow$ & Consensus & Expert opinion: combination widely used in rheumatology; combination \\
& & with low-dose MTX (e.g. $7.5-10$ mg/week is likely sufficient to reduce \\
formation of ADA and increase trough levels of adalimumab)
\end{tabular}




\section{Etanercept}

Instructions for use

Pre-treatment

- Physicians are encouraged to enrol their patients in a registry (if available)

- Objective assessment of the disease (such as PASI/BSA/PGA; arthritis)

- HRQoL (such as DLQI/Skindex-29 or -17)

- History and clinical examination should focus on prior exposure to treatments, malignancies, infection, congestive heart failure and neurological symptoms

- Recommended measures include:

- Check for malignancy, mainly skin cancer and pre-malignant lesions

- Check for lymphadenopathy

- Laboratory parameters (see Table 7)

- Exclusion of tuberculosis (see chapter 5.1 in long version)

- Check for evidence of active infection

- Contraception

During treatment

- Objective assessment of the disease (such as PASI/BSA/PGA; arthritis)

- HRQoL such as (DLQI/Skindex-29 or -17)

- Clinical examination should focus on lymphadenopathy, malignancies, especially skin cancer, premalignant lesions, risk factors for serious infections, congestive heart failure and neurological symptoms

- Recommended measures include:

- Laboratory parameters (see Table 7)

- Contraception

\section{Post-treatment}

- After discontinuation of etanercept, patients should be followed up with medical history and physical examination.

- Women of childbearing potential should be advised to use appropriate contraception to avoid becoming pregnant for three weeks after discontinuation of therapy.

Table 7 Recommended lab controls - etanercept

\begin{tabular}{|c|c|c|c|c|}
\hline \multirow[t]{2}{*}{ Parameter } & \multicolumn{4}{|l|}{ Period in weeks } \\
\hline & Pre-treatment & 4 & 12 & $\begin{array}{l}\text { Thereafter, } \\
\text { every 3-6 months }\end{array}$ \\
\hline Full blood count & $x$ & $x$ & $x$ & $x$ \\
\hline Liver enzymes & $x$ & $x$ & $\mathrm{x}$ & $x$ \\
\hline Serum creatinine & $x$ & $x$ & $x$ & $x$ \\
\hline Urine status & $x$ & & & \\
\hline Pregnancy test (urine) & $x$ & & & \\
\hline CRP & $x$ & & & \\
\hline $\mathrm{HBV} / \mathrm{HCV}$ & $x$ & & & \\
\hline HIV & $x$ & & & \\
\hline \multicolumn{5}{|c|}{$\begin{array}{l}\text { Not all tests may be necessary for all patients. Patient history, risk exposure and patient characteristics have } \\
\text { to be taken into account. Further specific testing may be required according to clinical signs, risk and } \\
\text { exposure. }\end{array}$} \\
\hline
\end{tabular}




\section{Therapeutic recommendations}

\begin{tabular}{|c|c|c|c|}
\hline \multicolumn{2}{|l|}{ Recommendation } & \multirow{2}{*}{$\begin{array}{l}\text { Strength of consensus } \\
\text { Strong consensus }\end{array}$} & \multirow{2}{*}{$\begin{array}{l}\text { Comment } \\
\text { Evidence and consensus based }\end{array}$} \\
\hline $\begin{array}{l}\text { We recommend etanercept as second-line* medication for the induction } \\
\text { and long-term treatment. }\end{array}$ & $\uparrow \uparrow$ & & \\
\hline $\begin{array}{l}\text { In general, a starting dose of } 50 \mathrm{mg} \text { once or twice weekly is used } \\
\text { depending on individual factors. }\end{array}$ & Statement & Strong consensus & Expert opinion \\
\hline For maintenance therapy $50 \mathrm{mg}$ once weekly is a commonly used dose. & Statement & Strong consensus & Expert opinion \\
\hline
\end{tabular}

${ }^{*}$ If phototherapy and conventional systemic agents were inadequate in response or if they are contraindicated or not tolerated.

\section{Therapeutic combinations}

\begin{tabular}{llll}
\hline Recommendation & & Strength of consensus & Comments \\
\hline Acitretin & $\uparrow$ & Consensus & Expert opinion: good safety profile assumed, possibly increased efficacy \\
\hline Ciclosporin & $\downarrow$ & Consensus & Expert opinion: increased risk of immunosuppression \\
\hline Fumaric acid esters & 0 & Strong consensus & No evidence available \\
\hline Methotrexate & $\uparrow$ & Consensus & $\begin{array}{l}\text { Evidence (additional benefit of adding MTX to etanercept compared to etanercept } \\
\text { monotherapy) and consensus based }\end{array}$ \\
\hline Ustekinumab & $\downarrow$ & Consensus & Expert opinion: increased risk of immunosuppression \\
\hline
\end{tabular}

\section{Infliximab}

Instructions for use

Pre-treatment

- Physicians are encouraged to enrol their patients in a registry (if available)

- Objective assessment of the disease (such as PASI/BSA/PGA; arthritis)

- HRQoL (such as DLQI/Skindex-29 or -17)

- History focusing on prior exposure to treatments. History and clinical examination should focus on malignancies, infection, congestive heart failure and neurological symptoms

- Recommended measures include:

- Check for skin cancer

- Check for lymphoadenopathy

- Laboratory parameters (see Table 8)

- Exclusion of tuberculosis (see chapter 5.1 in long version)

- Check for evidence of active infection

- Contraception

\section{During treatment}

- Objective assessment of the disease (such as PASI/BSA/PGA; arthritis)

- HRQoL (such as DLQI/ Skindex-29 or -17)

- Clinical examination should focus on malignancies, risk factors for serious infections, congestive heart failure and neurological symptoms

- Recommended measures include:

- Check for skin cancer

- Check for lymphoadenopathy

- Laboratory parameters (see Table 8)

- Contraception

Post-treatment

- After discontinuation of infliximab, patients should be followed up with medical history and physical examination 
Table 8 Recommended lab controls - infliximab

\begin{tabular}{lllll}
\hline & Period in weeks & & \\
\cline { 2 - 5 } & Pre-treatment & 2 & 6 & $\begin{array}{c}\text { Thereafter, prior } \\
\text { to each infusion }\end{array}$ \\
\hline Full blood count & $\mathrm{x}$ & & $\mathrm{x}$ & $\mathrm{x}$ \\
\hline Liver enzymes & $\mathrm{x}$ & $\mathrm{x}$ & $\mathrm{x}$ & $\mathrm{x}$ \\
\hline Serum creatinine & $\mathrm{x}$ & $\mathrm{x}$ & $\mathrm{X}$ & $\mathrm{x}$ \\
\hline Urine status & $\mathrm{x}$ & & \\
\hline Pregnancy test (urine) & $\mathrm{x}$ & & \\
\hline CRP & $\mathrm{x}$ & & \\
\hline HBV/HCV & $\mathrm{x}$ & & \\
\hline HIV & $\mathrm{x}$ & & \\
\hline $\begin{array}{l}\text { Not all tests may be necessary for all patients. Patient history, risk exposure and patient } \\
\text { characteristics have to be taken into account. Further specific testing may be required according to } \\
\text { clinical signs, risk and exposure. }\end{array}$ &
\end{tabular}

\section{Therapeutic recommendations}

\begin{tabular}{lll}
\hline Recommendation & Strength of consensus & Comment \\
\hline $\begin{array}{l}\text { We recommend infliximab as second-line* medication for the induction and } \\
\text { long-term treatment. }\end{array} \uparrow \uparrow$ & Strong consensus \\
\hline $\begin{array}{l}\text { We recommend using infliximab } 5 \mathrm{mg} / \mathrm{kg} \text { bodyweight continuously every } \\
\text { eight weeks during long-term treatment. }\end{array}$ & $\uparrow \uparrow$ & Strong consensus \\
\hline
\end{tabular}

*If phototherapy and conventional systemic agents were inadequate in response or if they are contraindicated or not tolerated.

\section{Therapeutic combinations}

\begin{tabular}{|c|c|c|c|}
\hline Recommendation & & Strength of consensus & Comments \\
\hline Acitretin & o & Consensus & No evidence available \\
\hline Ciclosporin & $\downarrow$ & Consensus & Expert opinion: increased risk of immunosuppression \\
\hline Fumaric acid esters & $\downarrow$ & Consensus & Expert opinion: increased risk of immunosuppression, lymphocytopenia \\
\hline Methotrexate & $\uparrow$ & Consensus & $\begin{array}{l}\text { Expert opinion: combination widely used in rheumatology; combination with low- } \\
\text { dose MTX (e.g. } 7.5-10 \mathrm{mg} / \text { week is likely sufficient to reduce formation of ADA and } \\
\text { increase trough levels of infliximab) }\end{array}$ \\
\hline Ustekinumab & $\downarrow$ & Consensus & Expert opinion: increased risk of immunosuppression \\
\hline
\end{tabular}




\section{Ustekinumab}

Instructions for use

\section{Pre-treatment}

- Physicians are encouraged to enrol their patients in a registry (if available)

- Objective assessment of disease (such as PASI/BSA/PGA; arthritis)

- HRQoL (such as DLQI/Skindex-29 or -17)

- History and clinical examination focusing on previous treatment exposure, UV light, malignancies, infections

- Recommended measures include:

- Check for skin cancer

- Check for lymphadenopathy

- Laboratory parameters (see Table 9)

- Exclusion of tuberculosis (see chapter 5.1 in long version)

- Evaluation of comorbidities including cardiovascular risk factors

- Check for evidence of active infection

- Contraception

During treatment

- Objective assessment of disease (such as PASI/BSA/PGA; arthritis)

- Patient oriented outcomes such as pruritus, DLQI and Skindex-29 or -17

- History and clinical examination focusing on malignancies and infections

- Recommended measures include:

- Check for skin cancer and lymphadenopathy

- Pregnancy

- Evaluation of treatment adherence

Post-treatment

- Patients should be followed up with medical history and clinical examination

- Contraception to be maintained for 15 weeks

Table 9 Recommended lab controls - ustekinumab

\begin{tabular}{lll}
\hline & \multicolumn{2}{l}{ Period in weeks/months } \\
\cline { 2 - 3 } & Pre-treatment & Thereafter every 3-6 months \\
\hline Full blood count & $\mathrm{x}$ & $\mathrm{x}$ \\
\hline Liver enzymes & $\mathrm{x}$ & $\mathrm{x}$ \\
\hline Serum creatinine & $\mathrm{x}$ & $\mathrm{x}$ \\
\hline Urine status & $\mathrm{x}$ & $\mathrm{x}$ \\
\hline Pregnancy test (urine) & $\mathrm{x}$ & \\
\hline CRP & $\mathrm{x}$ & \\
\hline HBV/HCV & $\mathrm{x}$ & \\
\hline HIV & $\mathrm{x}$ & \\
\hline $\begin{array}{l}\text { Not all tests may be necessary for all patients. Patient history, risk exposure and patient } \\
\text { characteristics have to be taken into account. Further specific testing may be required } \\
\text { according to clinical signs, risk and exposure. }\end{array}$
\end{tabular}




\section{Therapeutic recommendations}

\begin{tabular}{|c|c|c|c|}
\hline Recommendation & & Strength of consensus & Comment \\
\hline $\begin{array}{l}\text { We recommend ustekinumab as second-line medication* for the induction and } \\
\text { long-term treatment. }\end{array}$ & $\uparrow \uparrow$ & Strong consensus & Evidence and consensus based \\
\hline $\begin{array}{l}\text { We suggest using } 45 \mathrm{mg} \text { for patients with a bodyweight of } \leq 100 \mathrm{~kg} \text { and } 90 \mathrm{mg} \\
\text { ustekinumab for patients with a bodyweight of }>100 \mathrm{~kg} \text {. }\end{array}$ & $\uparrow$ & Strong consensus & Evidence and consensus based \\
\hline
\end{tabular}

Therapeutic combinations

\begin{tabular}{lcll}
\hline Recommendation & & Strength of consensus & Comments \\
\hline Acitretin & $\circ$ & Consensus & No evidence available \\
\hline Adalimuab & $\downarrow$ & Consensus & Expert opinion: increased risk of immunosuppression \\
\hline Ciclosporin & $\downarrow$ & Consensus & $\begin{array}{l}\text { Expert opinion: increased immunosuppression, anecdotal } \\
\text { evidence of increased toxicity }\end{array}$ \\
\hline Etanercept & $\downarrow$ & Consensus & Expert opinion: increased risk of immunosuppression \\
\hline Fumaric acid esters & $\circ$ & Consensus & No evidence available \\
\hline Infliximab & $\downarrow$ & Consensus & Expert opinion: increased risk of immunosuppression \\
\hline Methotrexate & $\circ$ & Consensus & No evidence available \\
\hline
\end{tabular}

\section{Special considerations and special patient populations}

\section{Tuberculosis (TB) screening before and during biologic treatment}

\begin{tabular}{lll}
\hline Recommendation & & Strength of consensus \\
\hline We recommend to do tuberculosis screening according to local regulations. & $\uparrow \uparrow$ & Strong consensus \\
\hline $\begin{array}{l}\text { For pre-screening, we recommend anamnesis including tuberculosis history; } \\
\text { a chest X-ray; TST and/or IGRA. }\end{array}$ & $\uparrow \uparrow$ & Strong consensus \\
\hline $\begin{array}{l}\text { We recommend remaining alert to the possibility of tuberculosis infection } \\
\text { during therapy. This includes taking medical history and might include } \\
\text { tuberculosis testing. }\end{array}$ & $\uparrow \uparrow$ & Strong consensus \\
\hline
\end{tabular}

\section{Hepatitis/other hepatological dysfunctions}

\begin{tabular}{|c|c|c|c|}
\hline Recommendation & & Strength of consensus & Comment \\
\hline $\begin{array}{l}\text { We recommend to screen patients for hepatitis } B \text { and hepatitis } C \text { before starting treatment } \\
\text { with a biologic or methotrexate. }\end{array}$ & $\uparrow \uparrow$ & Consensus & Expert opinion \\
\hline We recommend to screen patients for hepatitis B before starting treatment with ciclosporin. & $\uparrow \uparrow$ & Consensus & Expert opinion \\
\hline $\begin{array}{l}\text { If a positive marker is found, or the patient is known to have had prior infection we } \\
\text { recommend to consult a gastroenterologist with an interest in hepatology. }\end{array}$ & $\uparrow \uparrow$ & Weak consensus & Expert opinion \\
\hline We recommend to record all cases of reactivation/ exacerbation via drug registries. & $\uparrow \uparrow$ & Consensus & Expert opinion \\
\hline
\end{tabular}


HIV

\begin{tabular}{|c|c|c|c|}
\hline Recommendation & & Strength of consensus & Comment \\
\hline $\begin{array}{l}\text { We recommend the combination of anti-retroviral therapy with topical therapies (steroids, } \\
\text { vitamin D derivatives, or combination of both) as first-line treatment strategy for mild to } \\
\text { moderate psoriasis in HIV-infected patients. }\end{array}$ & $\uparrow \uparrow$ & Strong consensus & Expert opinion \\
\hline $\begin{array}{l}\text { For moderate-to-severe psoriasis, we recommend highly active anti-retroviral therapy with } \\
\text { skin-directed therapies, e.g. topicals and/or phototherapy (narrowband UVB mainly) as first- } \\
\text { line strategy. }\end{array}$ & $\uparrow \uparrow$ & Strong consensus & Expert opinion \\
\hline $\begin{array}{l}\text { We suggest acitretin as second-line treatment in addition to highly active anti-retroviral } \\
\text { therapy. }\end{array}$ & $\uparrow$ & Strong consensus & Expert opinion \\
\hline $\begin{array}{l}\text { We suggest using methotrexate or ciclopsorin or biologics only in patients with severe, } \\
\text { refactory psoriasis with well controlled HIV disease using HAART, in collaboration with a } \\
\text { specialist on HIV medicine. }\end{array}$ & $\uparrow$ & Strong consensus & Expert opinion \\
\hline $\begin{array}{l}\text { In cases showing lack of response, intolerance, or contraindication to conventional systemic } \\
\text { immunosuppressants, we suggest to consider biologics. }\end{array}$ & $\uparrow$ & Consensus & Expert opinion \\
\hline $\begin{array}{l}\text { We suggest using etanercept as biologic of choice in patients with severe, refactory } \\
\text { psoriasis with well controlled HIV disease using HAART. }\end{array}$ & $\uparrow$ & Consensus & Expert opinion \\
\hline
\end{tabular}

\section{Malignancies including lymphoma and skin cancer}

\begin{tabular}{|c|c|c|c|}
\hline Recommendation & & Strength of consensus & Comment \\
\hline $\begin{array}{l}\text { For patients with recent malignancy we recommend topical therapies, phototherapy (narrow } \\
\text { band UVB) * and/or acitretin. } \\
\text { *except cutaneous malignancies }\end{array}$ & $\uparrow \uparrow$ & Strong consensus & Expert opinion \\
\hline $\begin{array}{l}\text { In case of inadequate response to topical therapies, phototherapy, (narrow band UVB) and/ } \\
\text { or acitretin we suggest using MTX. }\end{array}$ & $\uparrow$ & Consensus & Expert opinion \\
\hline $\begin{array}{l}\text { We recommend to discuss the decision to initiate immunosuppressive therapies, in } \\
\text { psoriasis patients with a current or recent diagnosis of cancer in the previous five years case } \\
\text { by case with cancer specialists and to reach an informed decision, respecting the patient's } \\
\text { preference. }\end{array}$ & $\uparrow \uparrow$ & Consensus & Expert opinion \\
\hline $\begin{array}{l}\text { The elements to be taken into account for the shared decision are the type and staging of } \\
\text { cancer, the risk of recurrence and the burden of psoriasis in the individual patient. }\end{array}$ & Statement & Strong consensus & Expert opinion \\
\hline $\begin{array}{l}\text { In some cancers with relatively good prognosis, where flares of psoriasis cannot be } \\
\text { controlled by other therapies, we suggest to consider earlier introduction of } \\
\text { immunosuppressive therapies. In this case, we suggest methotrexate as the preferred } \\
\text { systemic agent to be used. }\end{array}$ & $\uparrow$ & Strong consensus & Expert opinion \\
\hline $\begin{array}{l}\text { In patients with concurrent cancer treatment who are treated with immunosuppressive } \\
\text { agents, we recommend to perform a search for pharmacological interactions in coordination } \\
\text { with the oncologist. }\end{array}$ & $\uparrow \uparrow$ & Consensus & Expert opinion \\
\hline
\end{tabular}

\section{Neurological disease}

\begin{tabular}{|c|c|c|c|}
\hline Recommendation & & Strength of consensus & Comment \\
\hline $\begin{array}{l}\text { We do not recommend TNF antagonist therapy in people with diagnosis of multiple sclerosis } \\
\text { or other demyelinating disease. }\end{array}$ & $\downarrow \downarrow$ & Strong consensus & Expert opinion \\
\hline $\begin{array}{l}\text { We recommend caution using TNF antagonist therapy in people with a first degree relative } \\
\text { with multiple sclerosis or other demyelinating disease. }\end{array}$ & $\uparrow \uparrow$ & Strong consensus & Expert opinion \\
\hline We suggest choosing fumaric acid esters in people with multiple sclerosis. & $\uparrow$ & Strong consensus & Expert opinion \\
\hline
\end{tabular}




\section{Ischaemic heart disease and congestive heart failure}

\begin{tabular}{lcc}
\hline Recommendation & \multicolumn{1}{c}{ Strength of consensus } & Comment \\
\hline We recommend not using CSA as a first-line treatment in patients with arterial hypertension. & $\downarrow \downarrow$ & Strong consensus \\
\hline $\begin{array}{l}\text { We suggest not using TNF antagonists in subjects with NHHA class III or IV congestive } \\
\text { heart failure. }\end{array}$ & $\downarrow$ & Consensus \\
\hline
\end{tabular}

\section{Diabetes mellitus}

\begin{tabular}{lcc}
\hline Recommendation & Strength of consensus & Comment \\
\hline $\begin{array}{l}\text { We suggest not using ciclosporin as a first-line treatment in patients with diabetes and/or } \\
\text { features of the metabolic syndrome. }\end{array}$ & $\downarrow$ & Consensus \\
\hline We suggest not using acitretin as a first-line treatment in patients with dyslipidaemia. & $\downarrow$ & Consensus \\
\hline
\end{tabular}

\section{Kidney failure/Renal impairment}

\begin{tabular}{|c|c|c|c|}
\hline Recommendation & & Strength of consensus & Comment \\
\hline $\begin{array}{l}\text { We recommend ensuring an accurate assessment of renal function in any patient with } \\
\text { known or suspected chronic kidney disease prior to therapy. }\end{array}$ & $\uparrow \uparrow$ & Strong consensus & Expert opinion \\
\hline $\begin{array}{l}\text { We recommend working in collaboration with the nephrologist when prescribing systemic } \\
\text { therapy in any patient with chronic kidney disease of stage } 3 \text { or more. }\end{array}$ & $\uparrow \uparrow$ & Strong consensus & Expert opinion \\
\hline $\begin{array}{l}\text { We suggest using methotrexate, acitretin, or biological therapy in people with chronic kidney } \\
\text { disease stage } 2-3 \text {. }\end{array}$ & $\uparrow$ & Consensus & Expert opinion \\
\hline $\begin{array}{l}\text { We recommend using a reduced dose of methotrexate in people with chronic kidney disease } \\
\text { stage } 3 .\end{array}$ & $\uparrow \uparrow$ & Consensus & Expert opinion \\
\hline In people with chronic kidney disease stage $4-5$ biologics can be used. & Statement & Strong consensus & Expert opinion \\
\hline $\begin{array}{l}\text { We recommend not using ciclosporin or fumaric acid esters in chronic kidney disease stage } \\
3 \text { or more. }\end{array}$ & $\downarrow \downarrow$ & Strong consensus & Expert opinion \\
\hline We recommend not using methotrexate in chronic kidney disease 4 or 5 . & $\downarrow \downarrow$ & Strong consensus & Expert opinion \\
\hline
\end{tabular}

\section{Wish for pregnancy in near future}

\begin{tabular}{|c|c|c|c|}
\hline Recommendation & & Strength of consensus & Comment \\
\hline $\begin{array}{l}\text { We recommend to advise the use of topical emollients, and low to moderate strength } \\
\text { corticosteroids of short duration as first-line therapy in women with a wish for pregnancy in } \\
\text { the near future or who are pregnant. }\end{array}$ & $\uparrow \uparrow$ & Consensus & Expert opinion \\
\hline $\begin{array}{l}\text { We recommend phototherapy with narrow band UVB for women who are inadequately } \\
\text { controlled by emollients and topical steroids who wish to become pregnant or who are } \\
\text { pregnant. }\end{array}$ & $\uparrow \uparrow$ & Strong consensus & Expert opinion \\
\hline $\begin{array}{l}\text { For pregnant women with severe psoriasis requiring systemic therapy for which the benefits } \\
\text { outweigh the risk, we suggest to consider etanercept. }\end{array}$ & $\uparrow$ & Strong consensus & Expert opinion \\
\hline $\begin{array}{l}\text { We recommend not using acitretin and methotrexate in women considering becoming } \\
\text { pregnant or who are pregnant. }\end{array}$ & $\downarrow \downarrow$ & Consensus & Expert opinion \\
\hline
\end{tabular}




\section{Psoriatic arthritis}

\begin{tabular}{|c|c|c|c|}
\hline Recommendation & & Strength of consensus & Comment \\
\hline $\begin{array}{l}\text { For relief of symptoms of psoriatic arthritis, we recommend NSAIDs. As a monotherapy, we } \\
\text { recommend NSAIDs for patients with mild and non-erosive articular as well as para-articular } \\
\text { involvement. }\end{array}$ & $\uparrow \uparrow$ & Strong consensus & Expert opinion \\
\hline $\begin{array}{l}\text { In patients with active joint involvement despite the usage of NSAIDs and potential poor } \\
\text { prognosis due to polyarthritis, increased inflammatory markers and erosive changes, we } \\
\text { recommend to start synthetic DMARDs early to prevent progression of disease and erosive } \\
\text { destruction of joints. }\end{array}$ & $\uparrow \uparrow$ & Consensus & Expert opinion \\
\hline $\begin{array}{l}\text { For inadequately responding patients after at least one synthetic DMARD, we recommend } \\
\text { the use of biological DMARDs in combination with synthetic DMARDs or as monotherapy. }\end{array}$ & $\uparrow \uparrow$ & Consensus & Expert opinion \\
\hline $\begin{array}{l}\text { We do not recommend synthetic monotherapy DMARDs for the treatment of axial } \\
\text { involvement or enthesitis, as they appear to be not effective in these patients. }\end{array}$ & $\downarrow \downarrow$ & Strong consensus & Expert opinion \\
\hline
\end{tabular}

\section{Newly approved medications and treatments in the pipeline}

The field of psoriasis treatments is evolving rapidly and several new treatments have been developed. For any guideline, it is a challenge to be up to date with the rapidly changing market of psoriasis treatments. New medications with very little use during regular clinical practice are difficult to assess with expert opinion knowledge. The guideline group has decided to focus on the licensed treatment options at the time point of the consensus conference. The group decided against a prospective inclusion of new drugs that are likely to be licensed in the near future, especially also in the light of lack of expert experience with these new drugs.

Since the cut off date for inclusion of approved medications in Europe (October 2014), secukinumab and apremilast have been granted market authorization by EMA. ${ }^{6,7}$ An update including newly approved medications is currently under preparation.

\section{References}

1 Atkins D, Best D, Briss PA et al. Grading quality of evidence and strength of recommendations. BMJ 2004; 328: 1490.

2 Jones J, Hunter D. Consensus methods for medical and health services research. BMJ 1995; 311: 376-380.
3 Murphy E, Black N, Lamping D, McKee C, Sanderson C. Consensus development methods, and their use in clinical guideline development: a review. Health Technol Assess 1998; 2: 88.

4 Andrews JC, Schunemann HJ, Oxman AD et al. GRADE guidelines: 15. Going from evidence to recommendation-determinants of a recommendation's direction and strength. J Clin Epidemiol 2013; 66: 726-735.

5 Andrews J, Guyatt G, Oxman AD et al. GRADE guidelines: 14. Going from evidence to recommendations: the significance and presentation of recommendations. J Clin Epidemiol 2013; 66: 719-725.

6 European Medicines Agency. CHMP summary of positive opinion for Cosentyx [Secukinumab]. 2014. Available at: http://www.ema.europa. eu:80/ema/index.jsp?curl=pages/medicines/human/medicines/003729/ smops/Positive/human_smop_000755.jsp\&mid=WC0b01ac058001d127 (last accessed: February 20, 2015).

7 European Medicines Agency. CHMP summary of positive opinion for Otezla [Apremilast]. 2014. Available at: http://www.ema.europa.eu/ema/index.jsp?curl=pages/medicines/human/medicines/003746/smops/Positive/ human_smop_000754.jsp\&mid=WC0b01ac058001d127 (last accessed: February 20, 2015).

\section{Supporting information}

Additional Supporting Information may be found in the online version of this article:

Data S1. Long version: European S3-Guidelines on the systemic treatment of psoriasis vulgaris - update 2015 - EDF in cooperation with EADV and IPC. 